\section{CHILD RESTRAINT SYSTEM USE IN MEXICO. WHAT DOES THE LAW SAY?}

${ }^{1} E$ Elisa Hidalgo-Solórzano, 'Lourdes Gómez-García, ${ }^{2}$ Ricardo Pérez-Núñez, Jjeffrey C Lunnen, ${ }^{3}$ Adnan Hyder. ${ }^{1}$ Center for Health Systems Research, National Institute of Public Health, Mexico (INSP); ${ }^{2}$ National Council for Accident Prevention Secretariat, Ministry of Health in Mexico; ${ }^{3}$ Johns Hopkins International Injury Research Unit, Johns Hopkins Bloomberg School of Public Health, Baltimore, Maryland, USA

\subsection{6/injuryprev-2016-042156.509}

Background During 2013, the mortality rate for Road Traffic Injuries (RTI) in Mexico was 13.4 per 100,000 habitants, about $1.8 \%$ of all deaths were children amongst children from 0-5 years of age as a result of a RTI while travelling as car occupants. Our objective is to analyse the current legislation regarding the use of Child Restraint Systems (CRS) and to estimate its prevalence in three Mexican cities.

Methods We performed a review of the existing Mexican legislation on CRS use; focused on six variables: age, weight and height of children, location inside the vehicle, use of restraints or car seat and anchorage system. As well, as a cross-sectional study conducted in 3 Mexican cities to determine the prevalence of CRS use. Two rounds of observation were performed in preschools, between August and December of 2014. We observed all vehicles that stopped in front of, or up to 5 metres away from the preschool's entrance to drop off children, we recorded information of the children, the vehicle, drivers and occupants.

Results In total, 68 traffic regulations were analysed in order to describe the Mexican legislation on children occupants of motor vehicles of 4 or more wheels. The most important finding was that the mandatory use of CRS is not defined in any of the reviewed regulations, however there is an agreement that children should travel in the rear seats. We observed a total of 3,019 motor vehicles and 3,508 children estimated to be 5 years of age or less. The prevalence of CRS use in both rounds was $16.24 \%$ (95\% CI: $15.04,17.51)$; $14.69 \%$ (95\% CI: $13.05,16.44)$ in round one and $17.76 \%(95 \% \mathrm{CI}: 16.01,19.61)$ in round two.

Conclusions In Mexico, since 2003 was established CRS use, and location of children in the rear seat, as a health policy applicable throughout the country. Twelve years later, is necessary for governments of the states and local authorities implement national health policies, to strengthen strategies of the Decade of Action for Road Safety.

\section{THE IMPACT OF SAFETY INSTITUTE OF AUSTRALIA LTD (SIA) OHS ACCREDITATION AND CERTIFICATION ACTIVITIES ON THE OHS PROFESSION IN AUSTRALIA - A STATUS}

'Gunther Paul, 'Warwick Pearse, ${ }^{2}$ Kevin Jones. 'Queensland University of Technology, Australia; '2 Safety At Work Blog

\subsection{6/injuryprev-2016-042156.510}

Background Following the development and implementation of professional qualifications standards, higher education standards have followed recently. In Australia, the national qualification standard (Australian Qualification Framework - AQF) has found a sibling in the SIA-proposed OHS (Occupational Health \& Safety) generalist, OHS professional and tertiary OHS education accreditation programs, which are commercially promoted through the Australian OHS Education Accreditation Board (AOHSEAB), an organisation 'auspiced' through the SIA (Safety Institute of Australia Ltd). While selling a basically commercial product in the first instance, the AOHSEAB claims that the implementation of accreditation of OHS professional education has positively affected the educational quality and professional outcomes of OHS education in Australia since 2012 (Pryor, 2015). Other claims by the Australian OHS education accreditation board were recently critically appraised by Paul \& Pearse (2015); such as the quality of the Health and Safety Professionals Alliance's (HaSPA) Body of Knowledge (BoK), which forms the basis for the accreditation process; or the quality of the professional project proposed by SIA (Pearse et al., 2015). HaSPA is another organisation associated with SIA.

Methods Recent published literature, articles in the SafetyAtWorkBlog, Safe Work Australia publications, and university OHS program information was searched, reviewed and analysed to determine changes in OHS education and the OHS profession from 2013 to 2015 in Australia, and whether these changes could be attributed to the professional accreditation program marketed through the AOHSEAB.

Results From information that is publicly available, it could not be determined that activities of the AOHSEAB had any impact on the quality of tertiary or vocational teaching of the OHS profession in Australia, or the profession as such. Recent changes in OHS programs in the tertiary education domain could as well be attributed to the requirements of the AQF framework and subsequent university internal accreditation of courses. Given that university program accreditation through the AOHSEAB is voluntary and not aligned with statutory frameworks, but potentially intended as a marketing/branding exercise, the response to the accreditation offer in the tertiary sector is fragmented $(21 / 32$ programs accredited). Moreover, in vocational training and professional certification, change will require statutory authority on the basis of a cohesive professional project. While it seems too early to determine any impact of such accreditation and certification activities on the OHS profession in Australia, the potential long term effects of accreditation and certification attempts need to be carefully considered and investigated.

Conclusions While there is wide consent across stakeholders that further professionalisation of the OHS occupation in Australia will require consolidated accreditation and certification structures, the current attempt by SIA has failed to provide the required solid professional foundation. It is also lacking statutory authority and support. As a consequence, the impact of the accreditation and certification framework has been marginal.

\section{Traffic Safety}

\section{Post Mon 1.12}

\section{KNOWLEDGE, ATTITUDES AND BEHAVIOURS ON CHILD PASSENGER SAFETY AMONG EXPECTANT MOTHERS AND PARENTS OF NEWBORNS: A QUALITATIVE AND QUANTITATIVE APPROACH}

${ }^{1}$ Xiangxiang Liu, ${ }^{2}$ Jingzhen Yang, ${ }^{3}$ Xiaojun Chen, ${ }^{4}$ Liping Li. ${ }^{1}$ Injury Prevention Research Centre, Medical College of Shantou University, China; ${ }^{2}$ Centre for Injury Research and Policy, the Research Institute at Nationwide Children's Hospital, USA; ${ }^{3}$ The First Affiliated Hospital of Shantou University Medical College, China; ${ }^{4}$ Injury Prevention Research Centre, Medical College of Shantou University, China

\subsection{6/injuryprev-2016-042156.511}

Background In China, road traffic injuries are the leading cause of death in children under age 14. Although children are 